\title{
Ukuran Gejala Pusat Data yang Dikelompokkan pada Penjualan Smartphone 2019-2020
}

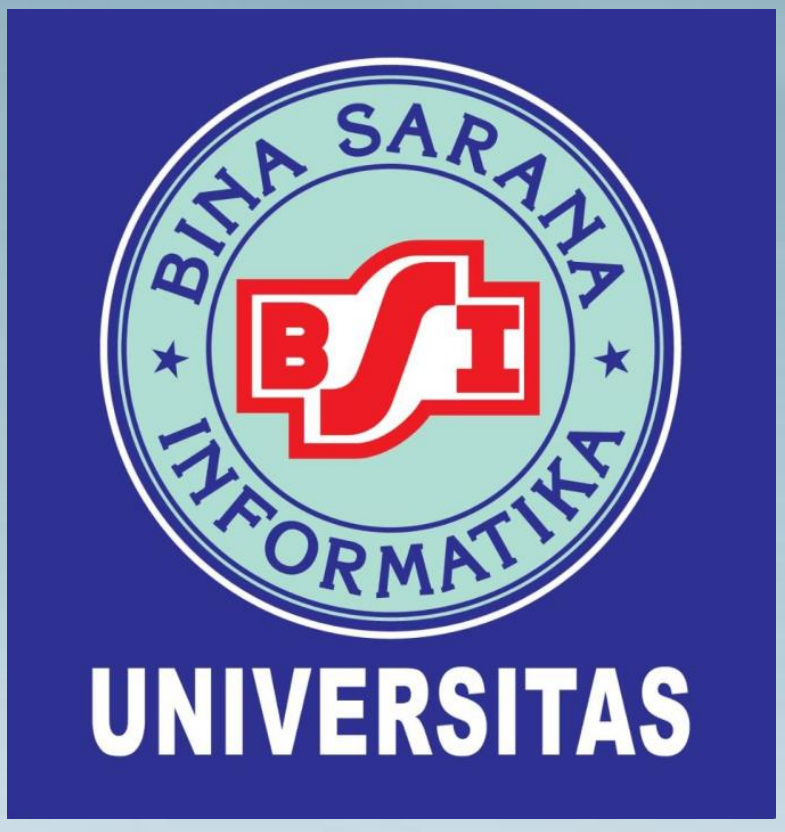

Kelompok 2

R. Arie Trihartanto

(12192779)

Samuel Gibson D

(12192096)

Theresia Meri Tarigan

(12193015)

Kelas 12.3A.27 


\section{Ukuran Gejela Pusat Data Dikelompokkan}

\section{Pengertian Ukuran Gejala Pusat}

Ukuran gejala pusat dapat disebut juga dengan nilai sentral atau nilai tendensi pusat. Nilai sentral adalah nilai dalam suatu rangkaian data yang dapat mewakili rangkaian data tersebut.

\section{Pengertian Data Dikelompokan}

Data yang dikelompokkan adalah data yang sudah disusun ke dalam sebuah distribusi frekuensi sehingga data tersebut mempunyai interval kelas yang jelas dan mempunyai titik tengah kelas.

Macam-macam Ukuran Gejala Pusat
a. Rata-rata Hitung (Mean)
d. kuartil
b. Median
e. Desil
c. Modus
f. Persentil

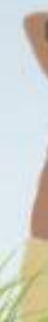


- Menentukan Ukuran Statistika Dengan

- Excel 2007/2010 Langkah-langkahnya:

- 1.Masukkan data pada range (A1:A21)

- 2.Pilih menu Data pada menu utama

- 3.Pilih Data Analysis

- 4.Pilih Deskriptive Statistics pada Data Analysis lalu klik OK

- Ketika Box Dialog muncul:

- ØPada kotak Input Range, sorot pada range A2:A21

- ØPada kotak Output Range, ketik C2

- ØBerikan tanda check pada Summary Statistics Kemdian klik $O K$ 


\begin{tabular}{|c|c|c|c|c|c|c|c|}
\hline & \multicolumn{4}{|c|}{ Tampilan Data Awal Excel } & \multicolumn{3}{|c|}{ Hasil Output Excel } \\
\hline & \multirow{3}{*}{ A } & & & & \multicolumn{3}{|c|}{ Tampilan ukuran gejala pusat data dikelompokkar } \\
\hline L & & B & c & \multirow[t]{2}{*}{ D } & \multicolumn{2}{|c|}{ Rata-rata } & \\
\hline 1 & & $x$ & y & & Mean & 42215.4 & \\
\hline & Penjualan Smartphone & 2019 & \multirow{2}{*}{\multicolumn{2}{|c|}{2020 Rata-rata }} & Standard Error & 6971,5168 & \\
\hline \multirow{2}{*}{\multicolumn{2}{|c|}{ Samsung }} & & & & Median & 42744 & \\
\hline & & $110 \angle 1$ & 53535 & 03411 & Mode & $\# \mathrm{~N} / \mathrm{A}$ & \\
\hline \multicolumn{2}{|c|}{4 Huawei } & 58436 & 42499 & 50467 & Standard Deviation & 15588,7855 & \\
\hline \multirow{2}{*}{\multicolumn{2}{|c|}{ Apple }} & 44569 & 40920 & 4)744. & Sample Variance & 243010232 & \\
\hline \multirow{2}{*}{\multicolumn{2}{|c|}{6 Xiaomi }} & & & & Kurtosis & $\begin{array}{r}-1,41076894 \\
037163802\end{array}$ & \\
\hline & & 27424 & 27817 & 27620 & Range & 36708 & \\
\hline \multirow{4}{*}{\multicolumn{2}{|c|}{7 Oppo }} & 29589 & 23949 & 26769 & Minimum & 26769 & \\
\hline & & & & & Maximum & 63477 & \\
\hline & & & & & Sum & 211077 & \\
\hline & & & & & Count & 5 & \\
\hline
\end{tabular}


- Menentukan Ukuran Statistika dengan SPPS

- Buka aplikasi SPSS. Ketik All Programs

- Close dialog Files, karena akan dilakukan analisis data sederhana

- Data view : Input data melalui lembar kerja dengan tab Data View

- Variabel view : mengedit dan melihat variable data pada lembar kerja

- Save : Menyimpan data yang telah diinput

- Pilih direktori penyimpanan dan simpan file data dengan nama

- File akan tersimpan

- Cara mengolah Data dengan SPSS

- Klik Analyze -> descriptive statistics -> descriptive

- Pilih Variabel yang akan dianalisi

- Klik options

- Klik ok pada jendela Descriptive

- Hasil analisis ditampilkan pada jendela output

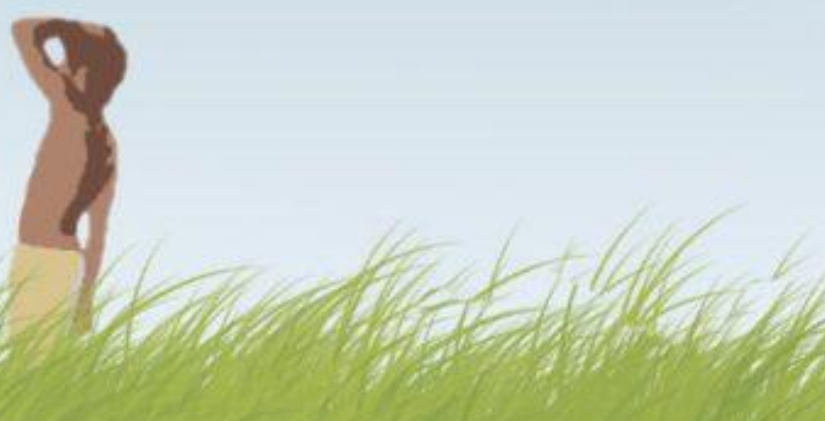




\section{Pengertian Ukuran Penyebaran Data}

Ukuran Penyebaran Data adalah ukuran yang menunjukkan seberapa jauh suatu data menyebar dari rata-ratanya. Ukuran Penyebaran data yang ada dalam materi statistika meliputi jangkauan, hamparan, dan kuartil.

\section{Pengertian Simpangan rata-rata}

Simpangan rata-rata adalah rata-rata jarak antara nilai-nilai data menuju rata-rata nya atau rata-rata penyimpangan absolut data dari rata-ratanya.

\section{Jenis Simpangan Rata-rata}

a. Data Tunggal

Digunakan hanya untuk data yang bersifat tunggal.

\section{Data Tunggal}

$$
S R=\frac{\sum_{i=1}^{n}\left|x_{i}-\bar{x}\right|}{n}
$$


b. Data berkelompok

Data Bergolong (Berkelompok)

$$
S R=\frac{\sum_{i=1}^{n} f_{i}\left|x_{i}-\bar{x}\right|}{\sum_{i=1}^{n} f_{i}}
$$

\section{Hasil Output Excel}

\section{Tampilan Data Awal Excel}

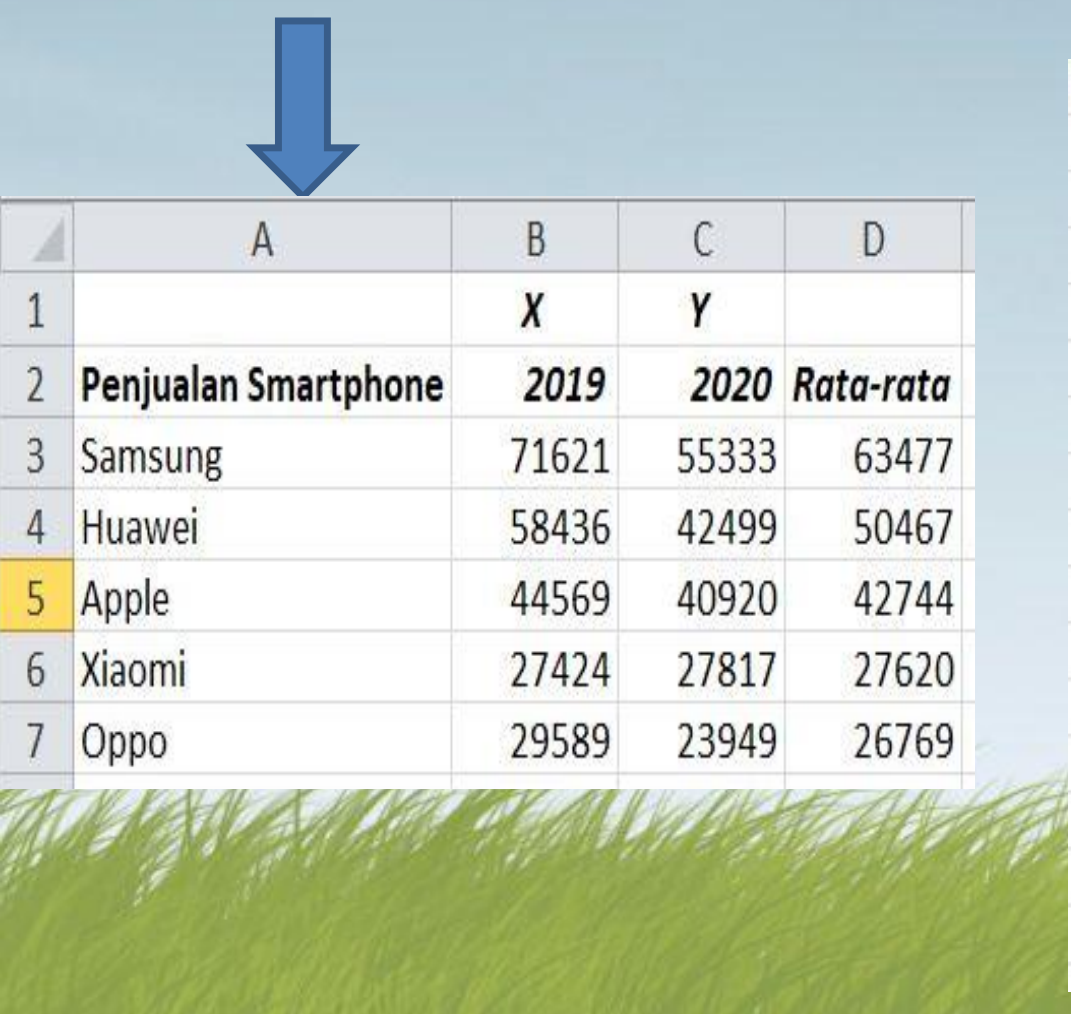

\begin{tabular}{|l|r|}
\hline \multicolumn{2}{|c}{ Rampilan ukuran gejala pusat data dike } \\
\cline { 1 - 2 } \\
\cline { 1 - 2 } & \\
\hline Mean & 42215,4 \\
\hline Standard Error & 6971,5168 \\
\hline Median & 42744 \\
\hline Mode & $\#$ N/A \\
\hline Standard Deviation & 15588,7855 \\
\hline Sample Variance & 243010232 \\
\hline Kurtosis & $-1,41076894$ \\
\hline Skewness & 0,37163802 \\
\hline Range & 36708 \\
\hline Minimum & 26769 \\
\hline Maximum & 63477 \\
\hline Sum & 211077 \\
\hline Count & 5 \\
\hline
\end{tabular}




\section{Tampilan Data Awal SPPS}

\begin{tabular}{|r|r|r|r|}
\hline & \multicolumn{1}{|l|}{} \\
\hline & 71621 & 55333 & 63477 \\
\hline \hline 2 & 58436 & 42499 & 50467 \\
\hline \hline 3 & 44569 & 40920 & 42744 \\
\hline \hline 4 & 27424 & 27817 & 27620 \\
\hline \hline 5 & 29589 & 23949 & 26769 \\
\hline \hline
\end{tabular}

\section{Output Hasil SPSS}

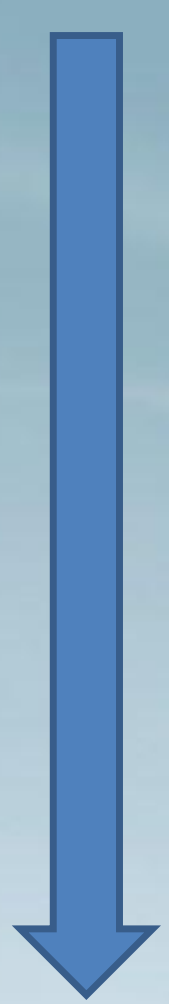

\section{Descriptive Statistics}

\begin{tabular}{|l|r|r|r|r|c|c|l|c|c|}
\hline & \multicolumn{1}{|c|}{$\mathrm{N}$} & Range & Minimum & Maximum & Sum & \multicolumn{2}{|c|}{ Mean } & Std. Deviation & Variance \\
\cline { 2 - 9 } & Statistic & Statistic & Statistic & Statistic & Statistic & Statistic & Std. Error & Statistic & Statistic \\
\hline Z & 5 & 36708 & 26769 & 63477 & 211077 & 42215,40 & 6971,517 & 15588,785 & 243010232,3 \\
Valid N (listwise) & 5 & & & & & & & & \\
\hline
\end{tabular}




\section{Sekian Dan Terimakasih}

